\title{
Nras and Kras mutation in Japanese lung cancer patients: Genotyping analysis using LightCycler
}

\author{
HIDEFUMI SASAKI, KATSUHIRO OKUDA, OSAMU KAWANO, KATSUHIKO ENDO, \\ HARUHIRO YUKIUE, TOMOKI YOKOYAMA, MOTOKI YANO and YOSHITAKA FUJII \\ Department of Surgery II, Nagoya City University Medical School, \\ 1 Kawasumi, Mizuho-cho, Mizuho-ku, Nagoya 467-8601, Japan
}

Received March 2, 2007; Accepted May 21, 2007

\begin{abstract}
Activating mutations of Ras gene families have been found in a variety of human malignancies, including lung cancer, suggesting their dominant role in tumorigenesis. Many studies have showed that the Kras gene is activated by point mutations in $\sim 15-20 \%$ of non-small cell lung cancers (NSCLCs), however, there are only a few reports on Nras mutations in NSCLC. We have genotyped Nras mutation status (n=195) and Kras mutation status $(\mathrm{n}=190)$ in surgically treated lung adenocarcinoma cases. The presence or absence of Nras and Kras mutations was analyzed by real-time quantitative polymerase chain reaction (PCR) with mutationspecific sensor and anchor probes. EGFR mutation status at kinase domain has already been reported. Nras mutation was found in 1 of 195 patients. This mutation was a G-to-T transversion, involving the substitution of the normal glycine (GGT) with cystein (TGT) and thought to be a somatic mutation. The patient was male and a smoker. Kras mutant patients $(11.1 \% ; 21 / 190)$ had a significantly worse prognosis than wild-type patients $(\mathrm{p}=0.0013)$. Eighty-two EGFR mutations at kinase domain had exclusively Nras or Kras mutations. Although Nras gene mutation might be one of the mechanisms of oncogenesis of lung adenocarcinoma, this was a very rare event. Further studies are needed to confirm the mechanisms of Nras mutations for the sensitivity of molecular target therapy for lung cancer.
\end{abstract}

\section{Introduction}

Lung cancer is the leading cause of cancer-related death in the world (1). Lung cancer was the leading indication for respiratory surgery (42.2\%) in 1998 in Japan (2). More than 15000 patients underwent surgical operation at Japanese

Correspondence to: Dr Hidefumi Sasaki, Department of Surgery II, Nagoya City University Medical School, Kawasumi 1, Mizuho-cho, Mizuho-ku, Nagoya 467-8601, Japan

E-mail: hisasaki@med.nagoya-cu.ac.jp

Key words: Nras, lung cancer, Kras, EGFR, genotype institutions in 1998 (2). Despite the advances made in surgery, chemotherapy, and radiotherapy, the overall 5-year survival rate still remains at only $15 \%$. Other therapeutic targets and agents are needed for the management of non-small cell lung cancer (NSCLC).

Ras oncogenes encode a family of membrane-associated proteins that regulate signal transduction on binding to a variety of membrane receptors. They play important roles in the regulatory processes of proliferation, differentiation, and apoptosis $(3,4)$. The ras inhibitor S-trans, trans-farnesylthiosalicylic acid chemosensitized human tumor cells (5). There are three functional Ras genes, Nras, Kras, and Hras, and all homologs carry constitutive activation of the Ras protein, which subsequently is held in GTP-bound status. These mutations have been described in various solid tumors. Kras mutation seems to be the most prominent ras mutations in patients with lung adenocarcinomas. Shigematsu et al reported that Kras gene mutations were present in 50 (8\%) of the 617 non-small cell lung cancers and were more frequently found in adenocarcinomas than in other histologic types $(12 \%$ versus $2 \%$; $<<0.001)$, in ever smokers than in never smokers $(10 \%$ versus $4 \%$; $=0.01)$, and in patients from the USA and Australia than in patients from Japan and Taiwan (12\% versus $5 \% ; p=0.0001$ ) (6). A previous report from USA showed that two of 14 lung tumors from smokers had Nras mutation (7), and a Japanese study that 7\% of NSCLC had Kras mutation, but there was no Nras mutation (8). However, these results were from a relatively small sample analysis.

The standard for experimental detection of mutations is direct sequencing of DNA samples from the tissues. However, for known mutations, real-time polymerase chain detection followed by melting curve analysis, using hybridization probes, is highly sensitive, rapid and an efficient alternative approach to mutation detection (9-11). To determine the Nras and Kras mutation status in Japanese lung carcinoma for screening and diagnostic purposes, we wanted to develop a faster and easy method to detect ras mutations. In this study, we investigated Nras mutation status at codon 12/13 and codon 61 by the realtime PCR assay using LightCycler (10), mutation-specific sensor and anchor probes. These probes were used in a previous study (12). We also investigated Kras mutation status at codon $12 / 13$ by the real-time RT-PCR assay using LightCycler. The findings were compared to the clinicopathologic features of lung cancer. 


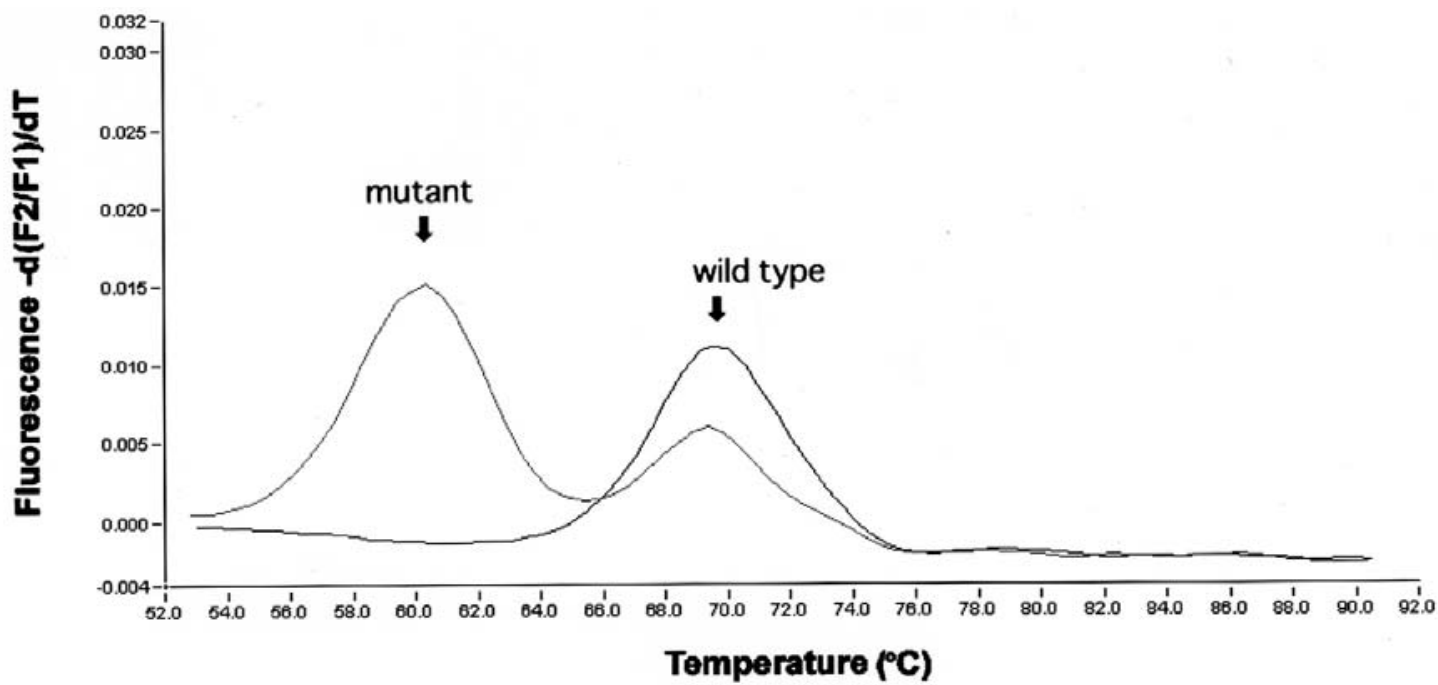

Figure 1. Detection of Kras mutation in cDNA extracted from lung cancer tissues. The negative derivative of the fluorescence (-dF/dT) versus temperature (Tm) graph shows peaks with different $\mathrm{Tm}$. The wild-type product showed a single peak at $69^{\circ} \mathrm{C}$, whereas the mutant type showed an additional peak at $60^{\circ} \mathrm{C}$.

\section{Patients and methods}

Patients. The study group included 195 lung adenocarcinoma patients who had undergone surgery at the Department of Surgery II, Nagoya City University Medical School Hospital between 1997 and 2006. All tumor samples were immediately frozen and stored at $-80^{\circ} \mathrm{C}$ until assayed. Genomic DNA was extracted from lung adenocarcinoma and matched with normal lung tissues using Wizard SV Genomic DNA purification kit according to the manufacturer's instructions. These samples were sequenced for EGFR kinase domain by ABI Prism 3100 analyzer (Applied Biosystems Japan Ltd., Tokyo, Japan) (13-15) and analyzed by ABI Prism Seq Scape version 2.1.1.

The clinical and pathological characteristics of the 195 lung adenocarcinoma patients were: 116 cases at stage I, 22 at stage II, and 47 at stage III-IV (10 unknown). The mean age was 64.8 years (range, 38-88). Among the 195 lung cancer patients, $101(51.8 \%)$ were male, $94(48.2 \%)$ were female, $102(52.3 \%)$ were non-smokers, and $93(47.7 \%)$ were smokers. Written informed consent was obtained from the patients, and the study was approved by the institutional ethics committee of the Nagoya City University Medical School.

PCR assays for Nras. The genotyping PCR reactions were performed using LightCycler DNA Master hybridization probe kit (Roche Molecular Biochemicals, Mannheim, Germany) in a $20-\mu 1$ reaction volume. The primer sequences for the Nras gene (codon 12/13) were: forward, 5-AGTACT GTAGATGTGGCTCGCC-3 and reverse, 5-CCTCACCTC TATGGTGGGATC-3. For the genotyping, sensor (TTG GAGCAGGTGGTGTTGGG-fluorescein) and anchor (LC Red 640 AAGCGCACTGACAATCCAGCTAATCCAGAA CC-phosphate) probes were used. The primer sequences for the Nras gene (codon 61) were: forward, 5-CACCCCCAG GATTCTTACAGA-3 and reverse, 5-GATGGCAAATAC ACAGAGGAAGC-3. For the genotyping, sensor (ATACAG CTGGACAAGAAGAG-fluorescein) and anchor (LC Red 640

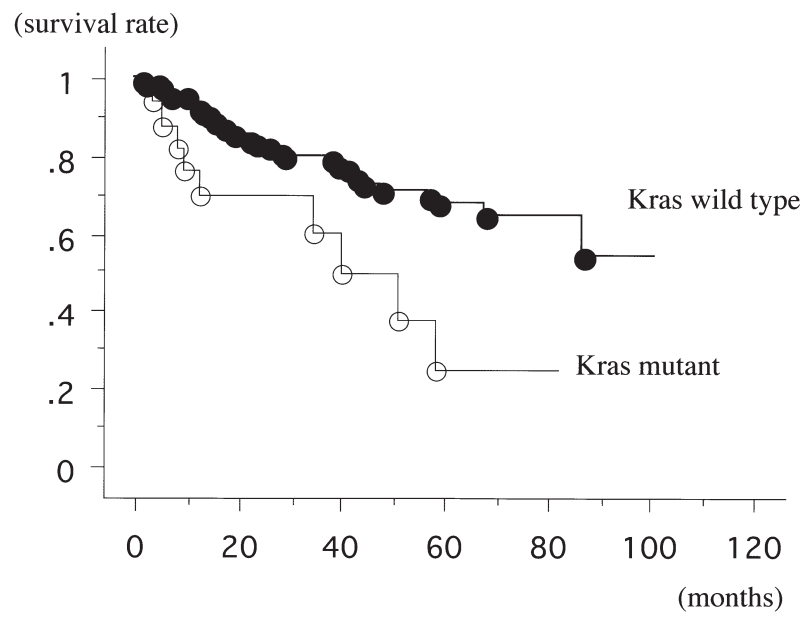

Figure 2. Kras mutant patients $(11.1 \% ; 21 / 190)$ had a significantly worse prognosis than wild-type patients (log-rank test, $\mathrm{p}=0.0013$ ).

AGTGCCATGAGAGACCAATACATGAGGA-phosphate) probes were used. Conditions for real-time PCR reaction were previously reported (12).

PCR assay for Kras codon 12/13. Total RNA was extracted from lung cancer tissues and adjacent non-malignant lung tissues using Isogen kit (Nippon gene, Tokyo, Japan) according to the manufacturer's instructions. RNA concentration was determined by spectrophotometer and adjusted to a concentration of $200 \mathrm{ng} / \mathrm{ml}$. RNA $(1 \mu \mathrm{g})$ was reverse transcribed by Superscript II enzyme (Gibco BRL, Gaithersburg, MD) with $0.5 \mu \mathrm{g}$ oligo $(\mathrm{dT})_{12-16}$ (Amersham Pharmacia Biotech Inc. Piscataway, NJ). Initially, several DNA samples were also sequenced and Kras mutation was found (16). These sets of cDNA were used as a positive and negative control for genotyping. DNA concentration was determined by spectrophotometer and adjusted to a concentration of 50 
Table I. Clinicopathological data of 190 lung cancer patients.

\begin{tabular}{|c|c|c|c|}
\hline \multirow[b]{2}{*}{ Factors } & \multicolumn{3}{|c|}{ Kras codon $12 / 13$ mutations } \\
\hline & Mutation patients & Wild-type patients & p-value \\
\hline Mean age (yrs.) 65.5 \pm 9.3 & 21 & 169 & \\
\hline \multicolumn{4}{|l|}{ Age } \\
\hline$\leq 60$ & $5(8.6 \%)$ & $53(91.4 \%)$ & 0.4785 \\
\hline$>60$ & $16(12.1 \%)$ & $116(87.9 \%)$ & \\
\hline \multicolumn{4}{|l|}{ Gender } \\
\hline Male & $15(14.4 \%)$ & $89(85.6 \%)$ & 0.1032 \\
\hline Female & $6(7.0 \%)$ & $80(93.0 \%)$ & \\
\hline \multicolumn{4}{|l|}{ Pathological subtypes } \\
\hline Adeno & $19(10.2 \%)$ & $167(89.8 \%)$ & 0.0611 \\
\hline BAC & $2(50.0 \%)$ & $2(50.0 \%)$ & \\
\hline \multicolumn{4}{|l|}{ Differentiation } \\
\hline Well & $6(6.5 \%)$ & $87(93.5 \%)$ & 0.0619 \\
\hline Moderately or & $10(15.6 \%)$ & $54(84.4 \%)$ & \\
\hline Poorly & & & \\
\hline \multicolumn{4}{|l|}{ Lymph node metastasis } \\
\hline N0 & $14(10.2 \%)$ & $124(89.8 \%)$ & 0.5557 \\
\hline $\mathrm{N}^{+}$ & $7(13.2 \%)$ & $46(86.8 \%)$ & \\
\hline \multicolumn{4}{|l|}{ Smoking status } \\
\hline Smoker & $14(14.7 \%)$ & $81(85.3 \%)$ & 0.1053 \\
\hline Non-smoker & $7(7.4 \%)$ & $88(92.6 \%)$ & \\
\hline \multicolumn{4}{|l|}{ Pathological stages } \\
\hline I & $8(6.8 \%)$ & $109(69.7 \%)$ & 0.019 \\
\hline II-IV & $13(17.8 \%)$ & $60(82.2 \%)$ & \\
\hline
\end{tabular}

$\mathrm{N}^{+}$, lymph node metastasis positive; adeno, adenocarcinoma.

$\mathrm{ng} / \mathrm{ml}$. We used $1 \mu \mathrm{l}$ of each DNA for LightCycler analyses. To ensure the fidelity of cDNA transcription, all samples were subjected to PCR amplification with oligonucleotide primers specific for the constitutively expressed gene glyceraldehyde-3-phosphate dehydrogenase. Five samples were excluded because of the quality of RNA. The Kras codon 12/13 mutation was analyzed by quantitative real-time RT-PCR, performed on LightCycler. The primer sequences for Kras gene (codon 12/13) were: forward, 5-AGA GAGGCCTGCTGAAAAT-3 and reverse, 5-AATTTGTTC TCTATAATGGTGAATATC-3. For the genotyping, sensor (LC Red 640-CTACGCCACCAGCTCCAAC) and anchor TCCACAAAATGATTCTGAATTAGCTGTATCGTCAA GGCACTCTTG-fluorescein) probes were used. Conditions for real-time PCR reaction were: one cycle of $95^{\circ} \mathrm{C}$ for $2 \mathrm{~min}$, 40 cycles of $95^{\circ} \mathrm{C}$ for $1 \mathrm{sec}, 55^{\circ} \mathrm{C}$ for $10 \mathrm{sec}$, and $72^{\circ} \mathrm{C}$ for $7 \mathrm{sec}$. At the end of the PCR reaction, samples were subjected to a melting analysis to confirm specificity of the amplicon. All positive samples from melting analysis were directly sequenced.
Statistical analyses. Statistical analyses were done using the Mann-Whitney U test for unpaired samples and the Wilcoxon signed rank-test for paired samples. Linear relationships between variables were determined by means of simple linear regression. Correlation coefficients were determined by rank correlation using Spearman's test and $\chi^{2}$ test. All analyses were done using the Stat-View software package (Abacus Concepts Inc., Berkeley, CA), and were considered significant when the p-value was $<0.05$.

\section{Results}

Sequence results for EGFR gene at kinase domain in lung cancer tissues. We analyzed the EGFR mutation status in kinase domain as previously reported (13-15). From the 195 lung cancer patients, 82 patients had the activating mutation. Twenty-eight were male $(n=101)$ and 54 were female $(n=94)$. Sixty-two were non-smokers $(n=98)$ and 20 were smokers $(n=97)$. Fifty-six patients were stage $I(n=116)$ and 24 were stage II-IV (n=69). Thus, EGFR mutation status at kinase 


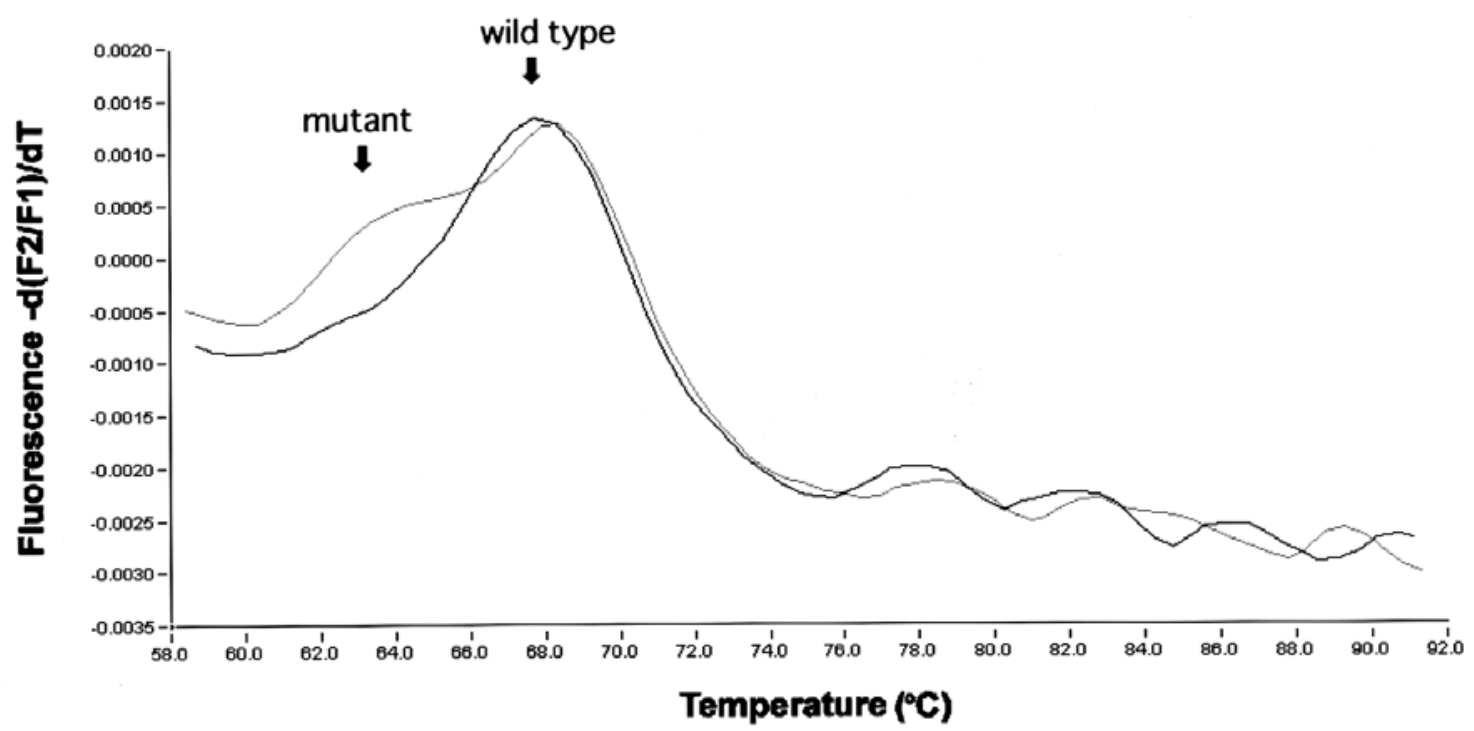

Figure 3. Detection of Nras mutation in DNA extracted from lung cancer tissues. The negative derivative of the fluorescence (-dF/dT) versus temperature (Tm) graph shows peaks with different $\mathrm{Tm}$. The wild-type product showed a single peak at $68^{\circ} \mathrm{C}$, whereas the mutant type showed an additional peak at $63^{\circ} \mathrm{C}$.

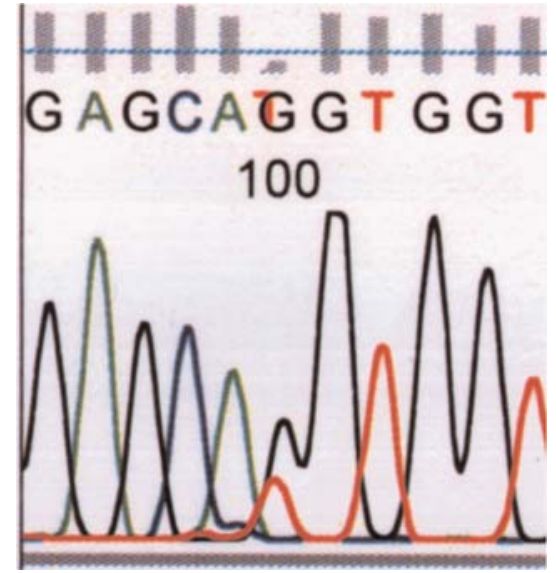

Figure 4. The sequencing data for Nras gene using RT-PCR (direct sequencing) method. The PCR products showed glycine (GGT) to cysteine (TGT) transition at codon 12 .

domain was significantly correlated with gender $(\mathrm{p}<0.0001)$ and smoking status $(\mathrm{p}<0.0001)$. There was a tendency towards better prognosis in $E G F R$ mutant patients than in $E G F R$ wild-type patients (log-rank test, $\mathrm{p}=0.0747$ ).

Genotyping of Kras codon 12/13 in lung cancer tissues. For genotyping, the anchor probe was matched for Kras wildtype. As shown in Fig. 1, the Kras wild-type PCR products showed a single peak at $69^{\circ} \mathrm{C}$, whereas the mutant-type showed an additional peak at $60^{\circ} \mathrm{C}$. From the 190 lung cancer patients, 21 patients had a Kras mutation (11.1\%) (Table I). Fifteen were male and 14 were smokers. Kras mutation was significantly higher in advanced stage patients (stage II-IV, $13 / 73)$ than in stage I patients $(8 / 117)(\mathrm{p}=0.019)$. There was a tendency towards a higher Kras mutation ratio in male ( $\mathrm{p}=0.1032)$. Kras mutant patients did not have Braf (17), erbB2 (15) (data not shown), and EGFR mutations at kinase domain. Thus, Kras mutation and EGFR mutation at kinase domain were exclusive. Of 21 samples, 19 were confirmed by direct sequencing. Of 19 Kras mutations, 11 (57.9\%) were G-to-T transversions.

Kras mutant patients $(11.1 \% ; 21 / 190)$ had a significantly worse prognosis than wild-type patients (log-rank test, $\mathrm{p}=0.0013$ ) (Fig. 2). Using the cox hazard regression model, pathological stage $(\mathrm{p}<0.0001)$ and Kras mutation $(\mathrm{p}=0.021)$ were independent prognostic factors.

Analysis of Nras mutations. For codon 12/13 genotyping, the anchor probe was matched for Nras wild-type. As shown in Fig. 3, the Nras wild-type products showed a single peak at $68^{\circ} \mathrm{C}$, whereas the codon 12 mutant type showed an additional peak at $63^{\circ} \mathrm{C}$. From the 195 lung cancer patients, only one patient had a Nras mutation. This was also confirmed by direct sequencing (Fig. 4). The adjacent matched-lung tissue was available and showed no additional peak from PCR assays, suggesting that these Nras mutations were somatic. This patient was a male and smoker. In total, 22 patients had ras mutations in adenocarcinomas. These ras and EGFR mutations at kinase domain were exclusive. There was a tendency towards a higher ras mutation ratio in smokers $(\mathrm{p}=0.0632)$ and in males $(\mathrm{p}=0.0714)$.

\section{Discussion}

We found only one Nras mutation in patients with adenocarcinoma. Somatic Nras or Kras mutations exclusively existed with $E G F R$ kinase domain mutations. Recent studies have shown that $E G F R$ gene mutations at kinase domain are common in lung cancers from never smokers and females with adenocarcinoma $(13-15,18,19)$, and correlated with sensitivity for $E G F R$ inhibitors $(20,21)$. On the other hand, in this study, there was a tendency towards a higher ras mutation ratio in smokers $(\mathrm{p}=0.0632)$ and males $(\mathrm{p}=0.0714)$. Our analysis suggested that the population of somatic ras mutations and the EGFR mutations at kinase domain in lung cancers were different. 
The mutational changes at critical codons of the ras genes result in loss of GTPase activity and gain of transforming ability in vitro and in vivo. Nras mutations are frequently observed in hematological malignancies. The incidence of Nras mutations is $\sim 20-30 \%$ in acute myeloid leukemia (AML) as well as myelodysplastic syndromes and $10 \%$ in acute lymphoblastic leukemia (ALL) (22-25), predominantly at codon 61. The prognostic relevance of the Nras alteration is more obvious in AML than in ALL (25). Mutations in members of the ras gene family, especially Nras, have been identified in cutaneous melanomas, although their reported frequency varies over a wide range (26-29), and especially seen at codon 61 . The ras gene family members are activated by point mutations at codon 12,13 or 61 in $20-30 \%$ of lung adenocarcinomas and $15-20 \%$ of all non-small cell lung cancers, but rarely in small cell lung cancers (30). Mutations in Kras account for $>90 \%$ of ras mutations of lung adenocarcinomas with $85 \%$ of Kras mutations affecting codon 12 (8). Characteristically, $70 \%$ of Kras mutations are G-to-T transversions, involving the substitution of the normal glycine (GGT) with either cysteine (TGT) or valine (GTT) (31). Uchiyama et al has shown that $7 \%$ of NSCLC had Kras mutation, but there was no Nras mutation (8).

Most ras and TP53 gene mutations in lung cancers are G-to-T transversions, molecular events that are linked to exposure to tobacco smoke carcinogens (32-34). Lung cancers that arise in never smokers rarely have $\operatorname{Kras}(\mathrm{G}-\mathrm{to}-\mathrm{T})$ gene mutations, and their TP53 gene mutations are seldom G-to-T transversions $(32,35)$, suggesting that these cancers arise in response to exposure to carcinogens other than those present in tobacco smoke. G-to-T transversions are also the most frequently detected mutations in activated ras genes in benzo[a]pyrene-induced mouse lung tumors (36).

The findings presented support the hypothesis that there are distinct molecular pathways that are involved in the pathogenesis of lung adenocarcinomas, one involving EGFR tyrosine kinase domain mutations (non-smoker, female) and the other involving the ras gene mutations (smoker, male). $K$-ras mutant lung cancer has been reported to show poorer clinical outcome when treated with EGFR inhibitor (37).

A wide range of mutation detection methodologies exist, of which sequencing has been considered the gold standard because of its ability to identify the specific DNA sequence change that has occurred. However, dideoxy-sequencing is rarely sensitive below a $10 \%$ mutant allele frequency, which corresponds to a threshold of $20 \%$ tumor cells heterozygous for a mutation (38). Melting curve analysis represents a significant advantage for mutation detection in tumor samples. The developments in dye technology have played a major role in the emergence of this methodology.

Different base substitutions produce differences in melting behavior. An advantage of performing melting curve analysis on a real-time PCR machine is that the PCR amplification and analysis are performed in one run within an hour and the results are available for analysis at the end of the run.

The frequency of Kras mutations in our sample set was higher than previous Japanese reports $(5,7,35)$. In our analysis, two melting curve positive patients were sequence wildtypes. A previous report indicated that melting curve analysis could detect as little as 5-6\% of mutant cell lines DNA diluted in normal DNA (39). Thus, melting curve analysis is a sensitive in-tube methodology to screen for mutations in clinical samples.

\section{Acknowledgements}

We would like to thank Mrs. Yuri Yamamoto for her excellent technical assistances. This study was supported by AstraZeneca Research Grant 2004 and Grants-in Aid for Science Research (Nos. 18659407, 18390381, 18790998) from the Ministry of Education, Culture, Sports, Science and Technology (MEXT), Japan.

\section{References}

1. Bunn PA Jr and Kato H: Current perspectives in the treatment of non-small cell lung cancer. Semin Oncol 28: 1-2, 2001.

2. Yasuda K, Ayabe H, Ide $H$ and Uchida Y: On behalf of the Japanese Association for Thoracic Surgery: Thoracic and cardiovascular surgery in Japan during 1998. Annual report by the Japanese association for thoracic surgery. Jpn J Cardiothorac Surg 48: 401-415, 1998.

3. Di Fiore PP, Pierce JH, Fleming TP, et al: Overexpression of the human EGF receptor confers an EGF-dependent transformed phenotype to NIH3T3 cells. Cell 51: 1063-1070, 1987.

4. Velu TJ, Beguinot L, Vass WC, et al: Epidermal-growth-factordependent transformation by a human EGF receptor protooncogene. Science 238: 1408-1410, 1987.

5. Gana-Weisz M, Halaschek-Wiener J, Jansen B, Elad G, Haklai R and Kloog Y: The Ras inhibitor S-trans, trans-farnesylthiosalicylic acid chemosensitizes human tumor cells without causing resistance. Clin Cancer Res 8: 555-565, 2002.

6. Shigematsu H, Lin L, Takahashi T, et al: Clinical and biological features associated with epidermal growth factor receptor gene mutations in lung cancers. J Natl Cancer Ins 97: 339-346, 2005.

7. Reynolds SH, Anna CK, Brown KC, et al: Activated protooncogenes in human lung tumors from smokers. Proc Natl Acad Sci USA 88: 1085-1089, 1991.

8. Uchiyama M, Usami N, Kondo M, et al: Loss of heterozygosity of chromosome $12 \mathrm{p}$ does not correlate with Kras mutation in non-small cell lung cancer. Int J Cancer 107: 962-969, 2003.

9. Sasaki H, Endo K, Konishi A, et al: EGFR mutation status in Japanese lung cancer patients: genotyping analysis using LightCycler. Clin Cancer Res 11: 2924-2929, 2005.

10. Wittwer CT, Herrmann MG, Moss AA and Rasmussen RP: Continuous fluorescence monitoring of rapid cycle DNA amplification. Biotechniques 22: 130-138, 1997.

11. Wittwer T, Ririe M, Andrew V, David A, Gungry A and Bali J: The LightCycler: a microvolume multisample fluorimeter with rapid temperature control. Biotechniques 22: 176-181, 1997.

12. Nakao M, Janssen JWG, Seriu T and Bartam CR: Rapid and reliable detection of $\mathrm{N}$-ras mutations in acute lymphoblastic leukemia by melting curve analysis using LigthtCycler technology. Leukemia 14: 312-315, 2000.

13. Paez JG, Janne PA, Lee JC, et al: EGFR mutations in lung cancer: correlation with clinical response to gefitinib therapy. Science 304: 1497-1500, 2004.

14. Endo K, Konishi A, Sasaki H, et al: Epidermal growth factor receptor gene mutation in non-small cell lung cancer using highly sensitive and fast TaqMan PCR assay. Lung Cancer 50: 375-384, 2005.

15. Sasaki H, Shimizu S, Endo K, et al: EGFR and erbB2 mutation status in Japanese lung cancer patients. Int J Cancer 118: 180-184, 2006.

16. Thomas RK, Baker AC, de Biasi RM, et al: High-throughput oncogene mutation profiling in human cancer. Nat Genet (In press).

17. Sasaki H, Kawano O, Endo K, et al: Uncommon V599E BRAF mutations in Japanese patients with lung cancer. J Surg Res 133: 203-206, 2006.

18. Lynch TJ, Bell DW, Sordella R, et al: Activating mutations in the epidermal growth factor receptor underlying responsiveness of non-small cell lung cancer to gefitinib. New Eng J Med 350: 2129-2139, 2004. 
19. Pao W, Miller V, Zakowski M, et al: EGF receptor gene mutations are common in lung cancers from 'never smokers' and are associated with sensitivity of tumors to gefitinib and elrotinib. Proc Natl Acad Sci USA 101: 13306-133011, 2004.

20. Mitsudomi T, Kosaka T, Endoh H, et al: Mutations of the epidermal growth factor receptor gene predict prolonged survival after gefitinib treatment in patients with non-small cell lung cancer with postoperative recurrence. J Clin Oncol 23: 2513-2520, 2005.

21. Sasaki H, Endo K, Mizuno K, et al: EGFR mutation status and prognosis for gefitinib treatment in Japanese lung cancer. Lung Cancer 51: 135-136, 2006.

22. Bashey A, Gill R, Levi S, Farr CJ, et al: Mutational activation of the N-ras oncogene assessed in primary clonogenic culture of acute myeloid leukemia (AML): implication for the role of N-ras mutation in AML pathogenesis. Blood 79: 981-989, 1992.

23. Yokota S, Nakao M, Horiike S, et al: Mutational analysis of the N-ras gene in acute lymphoblastic leukemia: a study of 125 Japanese pediatric cases. Int J Hematol 67: 379-387, 1998.

24. Kiyoi $H$, Naoe $T$, Nakano $Y$, et al: Prognostic implication of FLT3 and N-ras gene mutations in acute myeloid leukemia. Blood 93: 3074-3080, 1993.

25. Neubauer A, Dodge RK, George SL, et al: Prognostic importance of mutations in the ras proto-oncogenes in de novo acute myeloid leukemia. Blood 83: 1603-1611, 1994.

26. Ball NJ, Yohn JJ, Morelli JG, Norris DA, Golitz LE and Hoeffler JP: Ras mutations in human melanoma: a marker of malignant progression. J Investig Dermatol 102: 285-290, 1994.

27. Demunter A, Ahmadian MR, Libbrecht L, et al: A novel N-ras mutation in malignant melanoma is associated with excellent prognosis. Cancer Res 61: 4916-4922, 2001.

28. Omholt K, Kars Berg S, Platz A, Kanter L, Ringborg U and Hansson J: Screening of N-ras codon 61 mutations in paired primary and metastatic cutaneous melanomas: mutations occur early and persist throughout tumor progression. Clin Cancer Res 8: 3468-3474, 2002.
29. Cruz F III, Rubin BP, Wilson D, et al: Absence of BRAF and NRAS mutations in uveal melanoma. Cancer Res 63: 5761-5766, 2001.

30. Richardson GE and Johnson BE: The biology of lung cancer. Semin Oncol 20: 105-127, 1993.

31. Sekido Y, Fong KM and Minna JD: Progress in understanding the molecular pathogenesis of human lung cancer. Biochim Biophys Acta 1378: F21-F59, 1998.

32. Robles AI, Linke SP and Harris CC: The p53 network in lung carcinogenesis. Oncogene 21: 6898-6907, 2002.

33. Gearly R, Zhang L, Siegfried JM, Luketich JD and Keohavong P: Comparison of mutations in p53 and K-ras genes in lung carcinomas from smoking and nonsmoking women. Cancer Epidemiol Biomarkers Prev 8: 297-302, 1999.

34. Vahakangas KH, Bennettt WP, Castren K, et al: p53 and K-ras mutations in lung cancers from former and never-smoking women. Cancer Res 61: 4350-4356, 2001.

35. Toyooka S, Tsuda T and Gazdar AF: The TP53 gene, tobacco exposure, and lung cancer. Hum Mutat 21: 229-239, 2003.

36. You M, Candrian U, Maronpot R, Stoner G and Anderson M: Activation of the $\mathrm{Ki}$-ras protooncogene in spontaneously occurring and chemically induced lung tumors of the strain A mouse. Proc Natl Acad Sci USA 86: 3070-3074, 1989.

37. Eberhard DA, Johnson BE, Amler LC, et al: Mutations in the epidermal growth factor receptor and in KRAS are predictive and prognostic indicators in patients with non-small cell lung cancer treated with chemotherapy alone and in combination with erlotinib. J Clin Oncol 23: 5900-5909, 2005.

38. Ogino S, Kawasaki T, Brahmandam M, et al: Sensitive sequencing method for KRAS mutation detection by Pyrosequencing. J Mol Diagn 7: 413-421, 2005.

39. Krypuy M, Newnham GM, Thomas DM, Conron M and Dobrovic A: High resolution melting analysis for the rapid and sensitive detection of mutations in clinical samples: KRAS codon 12 and 13 mutations in non-small cell lung cancer. BMC Cancer 6: 295, 2006. 